\title{
El bacilo de Eberth lleva los médicos al tribunal
}

\author{
WALTER LEDERMANN D.
}

\section{The Eberth bacillus takes doctors to the Court}

En Estados Unidos es frecuente que los médicos deban concurrir al tribunal por juicios de malpractice, situación que, felizmente, no se repite todavía en Chile. Muy ocasionalmente, tanto allá como aquí, deben también acudir en calidad de peritos. Queremos recordar en este artículo dos casos históricos, por la calidad de los médicos involucrados, en que el bacilo de Eberth (me resisto a usar la absurda nomenclatura nueva de Salmonella y escribir Typhi con mayúsculas) al envenenar las aguas, motivara dos procesos interesantes desde el punto de vista médico más que jurídico.

El 21 de septiembre de 1843 la polvorienta diligencia se detuvo, con gran resoplido de caballos e interjecciones humanas, frente a la taberna de los Fuller, en North Boston, por entonces un caserío de sólo 43 habitantes, 18 millas al sur de Buffalo. De ella descendió trabajosamente un joven procedente de Warwick, desde donde había viajado unas $350 \mathrm{mi}-$ llas, tan enfermo que, sin detenerse en el bar a beber el tradicional trago, subió a tenderse al lecho, permaneciendo allí hasta el 19 de octubre, día de su muerte. Cinco días antes de esta fatídica fecha, otros casos de "fiebre maligna" comenzaron a aparecer en el poblado y siguieron haciéndolo hasta el 8 de noviembre. La tasa de ataque fue de $67 \%$ y la letalidad de $34 \%$. Todas las familias, salvo dos, fueron afectadas con uno y más casos, en algunas hasta siete 1).

Este brote de "fiebre epidémica" provocó justa alarma entre las autoridades y el "superintendente de los pobres" solicitó que se enviara a North Boston un médico de Buffalo. El oficial designado fue un joven médico de 31 años, graduado en Harvard, quien con el tiempo llegaría ser famoso. ¿Recuerdan, de sus clases de semiología, el "soplo de Austin Flint"? En sus propias palabras a bellows murmur, the bruit of the souffle, a puffing systolic heart sound. Austin Flint (1812-1866) llegó a ser uno de los más distinguidos médicos de su país, fundador de dos escuelas de medicina, gran profesor, notable escritor en diversas patologías y sobresaliente clínico9.

Imbuido en los métodos epidemiológicos de Louis $^{2}$, Austin Flint desarrolló en el poblado de North Boston una actividad frenética, durante su breve estadía de ocho horas el 5 de noviembre, comprendiendo una completa encuesta con el médico local Dr. Cramp, el examen de todos los enfermos y la autopsia de un niño recién fallecido. De regreso a la ciudad, se contactó con el clérigo de Warwick, solicitándole antecedentes del caso índice y de otros aparecidos en la región desde entonces. Al cabo llegó a la conclusión que la enfermedad en cuestión era fiebre tifoidea, expresándolo así en un par de artículos publicados en 1845 y $1852^{3,4}$.

Flint acertó, con toda probabilidad, en su diagnóstico de la enfermedad, pero erró en cuanto a su mecanismo de trasmisión, al escribir que "el joven dejó su hogar en Warwick con el principio de la tifoidea en su sistema; que este principio se desarrolló por la fatiga y la exposición a incidentes del viaje; que por estas circunstancias la enfermedad derivó a una mayor severidad y, quizás, también a una aumentada transmisibilidad; y que los casos subsecuentes de fiebre se debieron al contagio o infección así introducido en una comunidad estrechamente congregada y con libre intercambio entre unos y otros"... Atribuyendo el brote a una trasmisión persona a persona, fue contra la creencia popular de North Boston, que señalaba como fuente de contagio un pozo situado frente a la taberna de la familia Fuller. Según Flint, no había base para suponer "que alguna sustancia ponzoñosa introducida en el agua pudiera producir una epidemia de fiebre de ningún tipo", aunque treinta años después se retractó, en un ejemplo de honestidad científica, y reconoció la posibilidad de haberse diseminado el contagio a través del agua del pozo ${ }^{5}$.

La historia no terminaría aquí: faltaba el juicio, el proceso de los Stearns contra los Fuller. Una vieja rencilla separaba a ambas familias, al punto que en un momento los Fuller negaron a los Stearns el agua del pozo de la taberna, que era utilizada por todo el pueblo. Los Stearns reacondicionaron entonces su vieja noria, entrando al grupo de los privilegiados que tenían agua propia, junto a las familias de los Sprague y los Bailey, más pudientes y más lejanas de la taberna: por cierto que en este grupo no hubo tifoidea.

Olvidando a los Sprague y a los Bailey, y recordando la enemistad entre los Fuller y los Stearns, los lugareños usuarios del pozo de la taberna acusaron a los Stearns de haber envenenado esta fuente de agua. De hecho, los primeros casos se presentaron entre los Fuller, enfermando sus cinco niños. A medida que se producían los decesos, los ánimos se caldeaban y los rumores se convertían en francas acusaciones, causando una completa segregación de los Stearns. Con razón molestos, éstos terminaron por recurrir al tribunal de Buffalo, demandando a los Fuller por calumnia. Austin Flint no fue llamado 
al tribunal, hasta donde sabemos, pero participó indirectamente de los hechos al ordenar tomar una muestra de agua del pozo para su análisis. Aunque no creía en rumores, su abierto criterio científico le impidió desechar del todo esa posibilidad y envió una muestra a dos expertos químicos de la ciudad. En aquella época pre-pasteuriana se omitió toda precaución de asepsia y la muestra se tomó y envió en un jarro, sin duda bien limpio, pero que había sido previamente usado para guardar melaza. Los químicos no estaban en condiciones de hacer un estudio bacteriológico, ni se les habría pasado por la cabeza hacerlo, aunque pudieran, y lo único extraño que encontraron in much abundance fue sacarosa, que con buen sentido atribuyeron al contenido original del envase.

Este informe no fue del agrado de los lugareños, sosteniendo que la muestra tomada por Flint había sido sustraída y cambiada por otra de agua pura. El juez no opinó así y condenó a los Fuller a pagar a los Stearns una indemnización de cien dólares, suma nada despreciable para la época y considerando la situación financiera de los querellantes.

Lo irónico de la historia es que la prueba crucial, presentada por el célebre médico, no era válida. Hoy en día, con un hisopo de Moore bien cultivado, los Stearns habrían pasado un mal rato, aun siendo inocentes. Inocentes, pues está clarísimo que el enfermo de Warwick contaminó el pozo con sus deposiciones, apareciendo los casos secundarios a la tercera semana de su llegada a la taberna. Philip Satwell, quien en 1971 publicara una interesante crítica al método epidemiológico seguido por $\mathrm{Flint}^{6}$, se dio el trabajo de viajar al lugar de los hechos, logrando localizar la taberna original de los Fuller, que entonces seguía siendo taberna y se mantenía en pie más de un siglo después. Encontró que donde había estado el pozo existía ahora un poste telefónico, y la distancia entre éste y la taberna podía estimarse, a ojo, en unos quince metros, pero no menciona a qué distancia estaba la fosa negra para las excretas.

El pozo de los Fuller tuvo mal fin. Poco antes de la visita del Dr. Satwell hubo que cegarlo, al descubrirse que se había contaminado con bencina proveniente de un escape de una gasolinera cercana. No hay duda: estaba maldito.

El bacilo de Eberth culminó su carrera judicial en 1901, con motivo de la epidemia de Gelsenkirchen, que causó más de tres mil casos, con una letalidad del ocho por ciento ${ }^{7}$. Por entonces Gelsenkirchen era una importante ciudad industrial del valle del Ruhr, en Alemania, con gran necesidad de agua que, previa filtración, obtenía del río. Era sabido de todos, sin embargo, que cuando las industrias requerían más presión, la compañía abastecedora hacía entrar de prisa agua sin procesar, para llenar el estanque de emergencia. Al Fiscal le pareció evidente que la epidemia se había generado a partir de agua contaminada ingresada de esta manera, procediendo a demandar a la compañía. Al proceder así se basaba en la ley germánica que castigaba el suministro de alimentos contaminados, que pudieran alterar la salud o causar la muerte. Fueron acusados y llevados a juicio los directores E. Hegeler y K. Pfudel, así como el ingeniero M. Schmidt y el mecánico jefe H. Kiesendahl.

El juicio derivó en una formidable contienda científica, a raíz de una tinterillada de la defensa, al aducir que la ley era inaplicable, puesto que el agua no era un alimento. El abogado defensor citó, en apoyo de su tesis, al profesor de la Cátedra de Higiene de la Universidad de Munich. Este era nada menos que Rudolf Emmerich, el discípulo devoto y preferido de Max von Pettenkofer, a quien acompañara en su célebre experimentum crucis brindando con un cultivo de Vibrio cholerae. Pese a la magna diarrea sufrida en esa circunstancia, Emmerich seguía sustentando la Bodentheorie ${ }^{8}$, de acuerdo a la cual tanto el Vibrio como la Salmonella debían unirse a un misterioso principio terrestre para causar la enfermedad, siendo bacterias inofensivas cuando estaban simplemente en agua. Emmerich, con un raciocinio que hubiera hecho sonreír al viejo Sócrates, dijo, más o menos:

- ¿Es el agua esencial para la vida? Sí. ¿Es el aire esencial para la vida también? Sí, lo es. ¿Es uno u otro de estos elementos menos esencial? No; ambos son igualmente esenciales. ¿Y ahora... puede alguien sostener que el aire es un elemento? Tampoco lo es el agua.

El fiscal echó mano a una autoridad mayor y llamó a Robert Koch, cuyos argumentos, más razonables y fundamentados, hicieron que la corte aceptara el agua como alimento. La defensa recurrió a otro débil argumento y citó al profesor Arthur Springfield, autoridad en medicina forense, quien declaró que si bien el agua estaba contaminada, había falta de intencionalidad, pues la contaminación se debió a la ruptura accidental de una de las pipas, tesis que no pudo probarse.

El abogado defensor cambió de táctica y centró la discusión en la incapacidad del agua para trasmitir la fiebre tifoidea, de manera que no importaba si hubo o no filtración o si la pipa se rompió. Nuevamente fue llamado Rudolf Emmerich, quien empezó por manifestar su sorpresa por el hecho que en Prusia un fiscal trajera al tribunal una controversia puramente científica. Continuó con una extensa explicación de la Bodentheorie de su maestro, estableciendo que el bacilo de Eberth era inofensivo para el hombre, a menos que hubiera sufrido, por algunos meses, un proceso de maduración en el suelo, después del cual podría transmitirse por el aire. Terminó refiriéndose al experimentum crucis con que su maestro Von Pettenkofer demostrara en forma irrefutable su tesis.

- ¡Pero usted tuvo diarrea! - exclamó Koch.

- Diarrea, sí tuve, pero ninguna de las manifestaciones asociadas al cólera, como calambre de las extremidades...

- Perdón, Dr. Emmerich -dijo Koch- pero creo que aun conservo una carta suya estableciendo haber estado severamente enfermo y haber tenido calambres en las piernas.

Emmerich, que en ese juicio demostró poseer grandes cualidades para la abogacía (¿habrá errado su vocación?) desdeñó responder y trajo a colación cómo en 1834, durante la Peste negra, se había que- 
mado a miles de judíos bajo la falsa acusación de haber causado la plaga al envenenar los pozos. ¡Y hoy en día, en pleno siglo veinte, aun se trae hombres a juicio con similares acusaciones!

El fiscal llamó al profesor Karl Wilhelm von Drigalski (1871-1950), de Saarbrücken, quien empezó diciendo que las teorías de von Pettenkofer eran insensatas, para preguntar acto seguido cómo explicaba Emmerich la generación de brotes de tifoidea en barracas militares, que tenían pisos de concreto y no de tierra.

- Porque las tropas - replicó Emmerich - traen el bacilo, ya maduro, en el barro de sus botas.

Von Drigalski se tomó la cabeza a dos manos y abandonó el tribunal para volver a la paz de su laboratorio, suponemos que a preparar el medio de cultivo que inmortalizaría su nombre: el DrigalskiConradi litmus nutrose agar 9 .

Subió entonces al estrado el profesor Walter Kruse (1864-1943), célebre microbiólogo de Bonn, creador del asa de platino9. Este testigo fue bastante categórico:

- Las teorías de Max von Pettenkofer, siempre envueltas en un oscuridad mística y construidas sobre hipótesis drásticas, pero en completa contradicción con los hechos reales, son sólo el fruto de una fértil imaginación.

La defensa hizo unos débiles intentos por desacreditar a Koch, enrostrándole de paso su fracaso terapéutico con la tuberculina y dejándolo en evidencia como falsario, al enredarlo en un interrogatorio que podríamos recrear así :

- ¿Es efectivo, Dr. Koch, que en octubre de 1901 estuvo usted en Gelsenkirchen?

- Sí, señor. Vine comisionado por el Ministerio de Cultura para investigar las circunstancias de la epidemia.

- ¿Cuál fue la conclusión de sus investigaciones?

- Que la epidemia de tifoidea se produjo a consecuencias del llenado de la pipa o estanque de emergencia con agua del Ruhr no tratada.

- Aquí tenemos su informe, fechado el 21 de octubre de 1901. ¿Es la fecha correcta, Dr. Koch?

- Sí, Herr Anwalt.

- Y como explica usted, Herr Doktor, lo sostenido por usted mismo tres días antes, en su conferencia pública del 18 de octubre, cuando expresara que la contaminación del agua se debía a la ruptura accidental de dicho estanque y no a la introducción deliberada de agua impura?

- En aquellos días, Herr Anwalt, la opinión pública estaba tan inflamada contra la gente de la compañía de agua, que no estimé prudente añadir leña al fuego expresando mi verdadero pensamiento.

- ¿De manera que mintió, Herr Doktor?

- En cierto modo y por razones de pública conveniencia.

En este momento el abogado defensor se habrá vuelto, desdeñoso y triunfal a la vez, hacia el fiscal, diciéndole :

- ¡Su testigo, señor Fiscal!

La maniobra, empero, no prosperó y la defensa se vio obligada a echar marcha atrás y declarar que la epidemia no era culpa de los hombres, sino un Acto de Dios; que la Bodentheorie no estaba pasada de moda y que, en todo caso, no era de la competencia del tribunal resolver sobre esta materia científica, ni mucho menos basándose sólo en la autoridad de Koch o de Von Pettenkofer, puesto que aún había muchos problemas sobre el cólera y la tifoidea que ignoramus (sic). Y luego agregó, no sin cierta lógica, que el testimonio de Koch pesaba mucho por el prestigio de que gozaba en ese momento, pero si este juicio se hubiera celebrado once años antes... ¿no habría aparecido von Pettenkofer como la máxima autoridad en el tema, apoyado por todo el mundo médico, oficial y no oficial, girando a su alrededor "como estrellas en torno al sol"? ¿Y quién podría decir si en diez años más la escuela de Koch no se habrá eclipsado, como hoy parece ocurrirle a la de von Pettenkofer?

Emmerich y el abogado defensor triunfaron, pues no pudo probarse que la contaminación del agua hubiese causado la epidemia. El fiscal, que pedía prisión para los tres acusados, retiró los cargos de "dañar la salud y causar riesgo vital", cambiándolos por el de "adulterar un alimento". Se les impuso a Pfudel y a Schmidt una multa de 1.500 marcos, a Hegeler de 1.200 y a Kiesendahl de apenas 200.

La epidemia tuvo lugar en 1901. El proceso se abrió el 4 de julio de 1904 y se cerró al décimo día de audiencias, por requerirse información técnica. Se reabrió el 14 de noviembre y se dictó sentencia el 30 del mismo mes, un lapso brevísimo para un proceso judicial. Ningún otro ha reunido, en tan escaso término, tal constelación de astros médicos.

\section{Bibliografía}

1.- Evans A. Two errors in enteric epidemiology: the stories of Austin Flint and Max von Pettenkofer. Rev Inf Dis 1985; 7 (3): 434-40.

2.- Lilienfeld A, Lilienfeld D. What else new? An historical excursion. Am J Epidemiol 1977; 105 (3): 169-79.

3.- Flint A. Account of an epidemic fever which ocurred at North Boston, Erie County, New York, during the months of October and November 1843. Amer J Med Scie, New Series 1845; 10: 21-35.

4.- Flint A. The transportation and diffusion, by contagion, of Typhoid Fever. In: Clinical Reports on Continued Fever. Derby \& Co, Buffalo 1852; pp. 377-90.

5.- Flint A. Relation of water on the propagation of fever. Reports and papers presented at meeting of the American Public Health Association in the year 1873. New York 1875.

6.- Satwell P. The case of poisoned well. A reconstruction based on three papers by Austin Flint. Am J Epidemiol 1971; 93 (3): 150-6.

7.- Howard-Jones N. Gelserkirchen typhoid epidemic of 1901. Robert Koch and the dead hand of Max von Pettenkofer. Br Med J 1973; 1: 103-5.

8.- Von Pettenkofer M. Die Bodentheorie. Zeitschrift für Biologie 1865; 1: 322.

9.- Dorland's Illustrated Medical Dictionary. $24^{\text {th }}$ ed, WB Saunders Co, Phi 1951. (Ver entradas correspondientes : Flint, Drigalski, Kruse). 